\title{
Fiber Traction Printing: A 3D Printing Method of Continuous Fiber Reinforced Metal Matrix Composite
}

\author{
Xin Wang ${ }^{1,2}$, Xiaoyong Tian ${ }^{1,2^{*}}$, Qin Lian ${ }^{1,2}$ and Dichen $\mathrm{Li}^{1,2}$
}

\begin{abstract}
A novel metal matrix composite freeform fabrication approach, fiber traction printing (FTP), is demonstrated through controlling the wetting behavior between fibers and the matrix. This process utilizes the fiber bundle to control the cross-sectional shape of the liquid metal, shaping it from circular to rectangular which is more precise. The FTP process could resolve manufacturing difficulties in the complex structure of continuous fiber reinforced metal matrix composites. The printing of the first layer monofilament is discussed in detail, and the effects of the fibrous coating thickness on the mechanical properties and microstructures of the composite are also investigated in this paper. The composite material prepared by the FTP process has a tensile strength of $235.2 \mathrm{MPa}$, which is close to that of composites fabricated by conventional processes. The complex structures are printed to demonstrate the advantages and innovations of this approach. Moreover, the FTP method is suited to other material systems with good wettability, such as modified carbon fiber, surfactants, and aluminum alloys.
\end{abstract}

Keywords: 3D printing, Metal matrix composite, Capillarity, Continuous carbon fiber

\section{Introduction}

The metal matrix composite (MMC) is a revolutionary, futuristic type of metal [1-3], which has been widely used in the aerospace and automobile industries since the 1980s. It is considered to be an alternative material to aluminum and titanium alloys [1] because of its high specific strength, high specific modulus, corrosion resistance, and oxidation resistance, etc. [4-8]. However, MMC has several challenges, principally in its high cost and machining complexity $[4,9]$, which limit its further application_ENREF_7. Additive manufacturing has advantages in its flexible process, the simplicity of the tool, and direct molding [10-13], which can overcome the current difficulties in the preparation of metal matrix composites. The research on 3D printing of MMCs has

\footnotetext{
*Correspondence: leoxyt@mail.xjtu.edu.cn

'State Key Laboratory of Manufacturing Systems Engineering, Xi'an

Jiaotong University, Xi'an 710049, China

Full list of author information is available at the end of the article
}

been absent until now, so making it necessary to develop novel technologies.

$\mathrm{Pb}$ is the most common radiation shielding material [14-16], but it is not a suitable 3D-printable material because of its poor wettability. A hypereutectic alloy of $\mathrm{SnPb}$, which has the characteristics of low melting point, good fluidity, and wettability, can be used for 3D printing [17]. Making a $\mathrm{SnPb}$ alloy into a composite could greatly improve its mechanical properties [18-20], physical properties [21], and the ability to use direct molding by means of the additive manufacturing process.

Here we propose a novel 3D printing approach of continuous fiber reinforced metal matrix composites, which uses the fiber bundle to control the morphology via wetting with a liquid metal. The wetting behavior effectively suppresses the agglomeration of the liquid metal, and the morphology can be controlled. The process is notable for the classical 3D printing process of thermoplastic composites. At the same time, the challenges in conventional preparation methods, such as the direct structuring and uniform distribution of fibers, can be solved by 
this process. The approach is suited to other material systems with good wettability, such as fiber, surfactants, and aluminum alloys. It provides a solution to promote the development of the MMC and its low-cost applications.

In this paper, the printing of the first layer monofilament is discussed in detail, and the effects of a fibrous coating thickness on the mechanical properties and microstructures of the composite are also investigated. Additionally, the complex structural composites were printed.

\section{Materials and Method}

\subsection{Materials}

The $2 \mathrm{~mm}$ diameter $\mathrm{Sn}_{50} \mathrm{~Pb}_{50}$ (wt.\%) alloy wire, the melting temperature of which is $189^{\circ} \mathrm{C}$, and T300B carbon fibers were used as raw materials. To meet the requirements of the process, the carbon fibers were treated by electroplating two successive layers of metallic coating, $1 \mu \mathrm{m}(0.2 \mu \mathrm{m}) \mathrm{Ni}$ coating and $2 \mu \mathrm{m}(0.8 \mu \mathrm{m}) \mathrm{Cu}$ coating $(3.0 \mathrm{Cu}-\mathrm{Cf}$ and $1.0 \mathrm{Cu}-\mathrm{Ccf})$, wherein the $\mathrm{Ni}$ coating was to improve the overall tensile strength of the coated fiber [18]. The coated continuous carbon fiber bundles were commissioned and fabricated by the Suzhou Institute of Nano-Tech and Nano-Bionics, and the properties are shown in Table 1.

Since the actual printing process was performed in air, the oxidation of the $\mathrm{Cu}$ coating and the liquid metal matrix could not be ignored. Oxygen contamination (even at ppm levels) can have a dramatic effect on the surface tension of metals [22]. Therefore, soldering flux, which eliminates the oxide layer and decreases the wetting angle, was utilized to modify the $\mathrm{Cu} / \mathrm{Ni}$ coated carbon fiber. More importantly, the soldering flux forms a protective layer on the surface of the fiber before being wetted by the liquid metal. In the printing process, the soldering flux transforms to a gas or floats above the liquid metal.

\subsection{Method}

A novel additive manufacturing approach of continuous fiber reinforced metal matrix composites, fiber traction printing (FTP), is proposed in this paper. By using the

Table 1 The parameters of carbon fiber

\begin{tabular}{llll}
\hline & Fiber quantity & $\begin{array}{l}\text { Tensile strength } \\
\text { (MPa) }\end{array}$ & $\begin{array}{l}\text { Tensile } \\
\text { modulus } \\
(\mathbf{G P a})\end{array}$ \\
\hline T300B & $1 \mathrm{k}$ & 3530 & 230 \\
$\mathrm{Cu}$ & - & 227 & - \\
$1.0 \mathrm{Cu}-\mathrm{Cf}$ & $1 \mathrm{k}$ & 3000 & 230 \\
$3.0 \mathrm{Cu}-\mathrm{Cf}$ & $1 \mathrm{k}$ & 2900 & 230 \\
\hline
\end{tabular}

wetting behavior between the fiber and liquid metal, and the action of the elasto capillary force [23], porosities in the fiber bundle are filled with liquid metal, which forms a dense internal structure and a good interface. The liquid metal is then uniformly attached to the outside of the fiber bundle and the monofilament is drawn from the molten cavity. Finally, the layers are superposed to integrate. The formation of the interface can be controlled because the additive manufacturing approach is a fast, dynamic, and partial process that differs from traditional slow, static, and integral methods. Moreover, porosities and cracks generated in metal printing [24] can be suppressed due to the capillarity.

The FTP process stems from the classic thermoplastic composite printing process and has some similarities. For example, they are both wire-based and fused-deposition processes that lead to similar devices. However, there are a number of differences in the mechanisms of these two processes, such as the state of the matrix in the molten cavity and the combination and deposition mechanisms, which are discussed in detail later. According to the different positions of the fiber bundle in the forming process, the entire process can be divided into four stages (Figure 1).

First, the liquid metal rises inside the continuous fiber bundle, which is above the liquid level, and the porosities inside the fiber bundle are filled by capillary action. Second, when the surface coating of the fiber bundle and the liquid metal are sufficiently wetted inside the molten cavity, the final interface forms. Third, the liquid metal packages the fiber bundle homogeneously (Figure 2(b)) under the action of gravity and internal friction. Finally, the printed monofilament is superposed and forms a component.

Based on this mechanism, the process could be extended to other composites, which exhibit a favorable wetting performance between the fiber and the matrix.

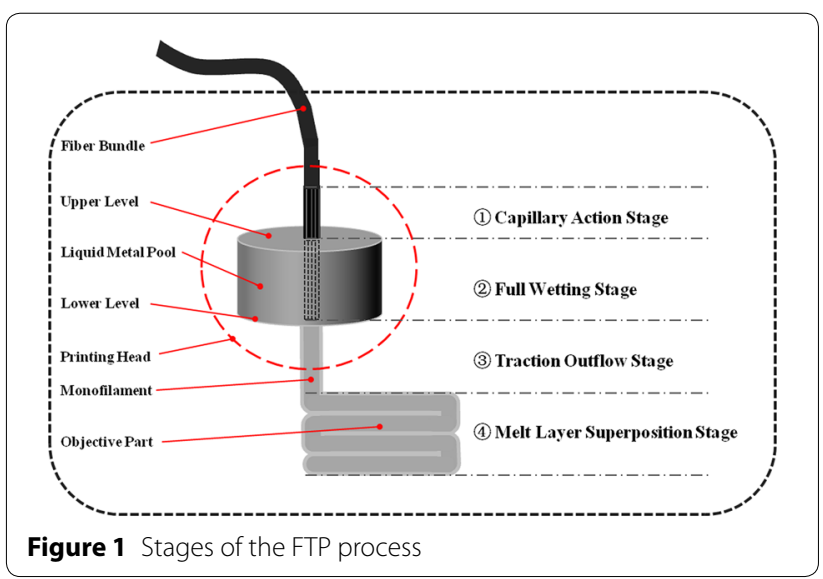



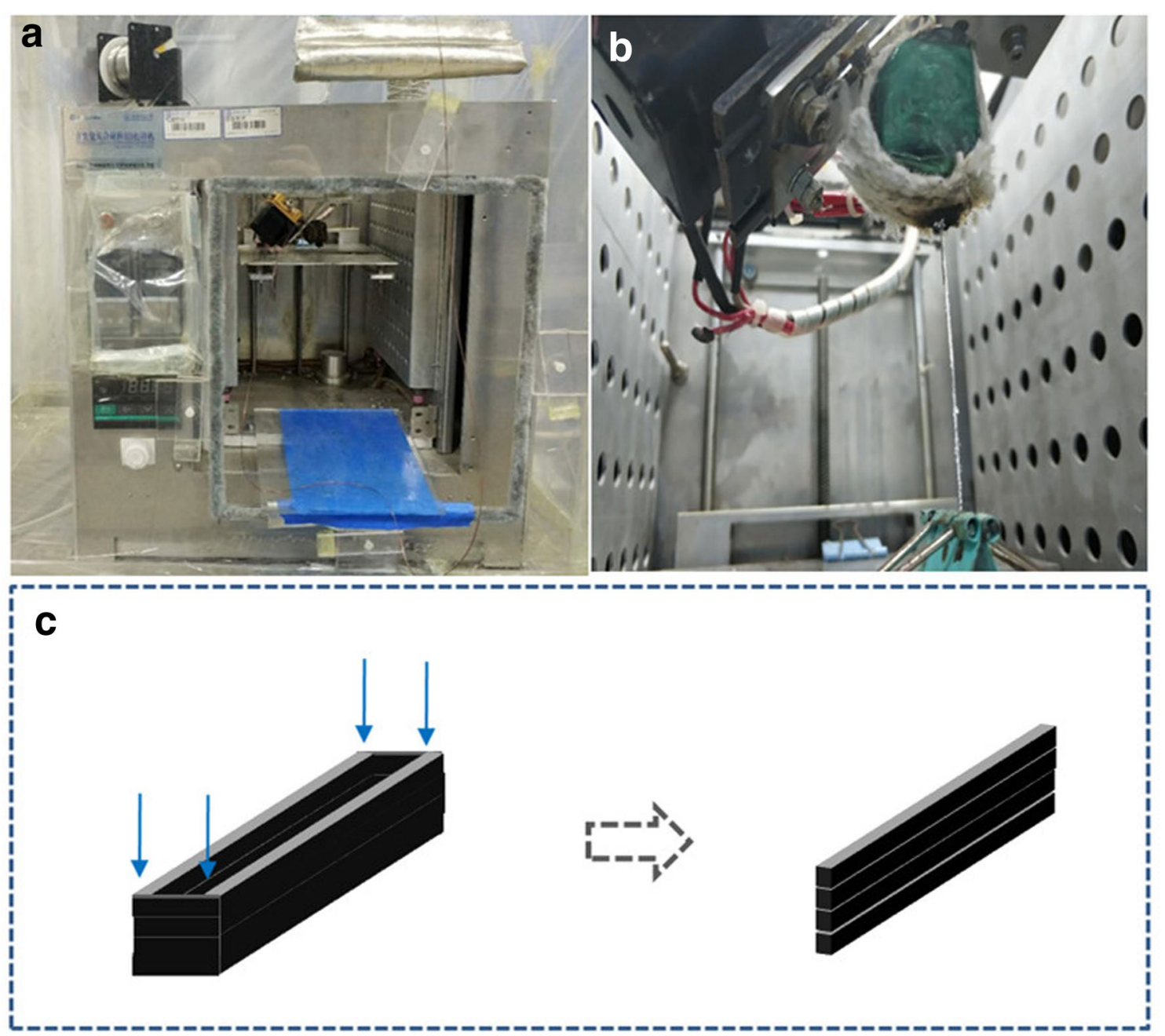

Figure 2 (a) Experimental platform; (b) The monofilament morphology in traction outflow stage; (c) The printed composite and the tensile specimen

\subsection{Fabrication of $\mathrm{C}_{\mathrm{f}} / \mathrm{Sn}_{50} \mathrm{~Pb}_{50}$ Composite}

The experimental platform is shown in Figure 2(a). The $\mathrm{Sn}_{50} \mathrm{~Pb}_{50}$ alloy wires and $\mathrm{Cu}$ coated carbon fiber were used for the FTP methodology. The composites were printed along the width direction and the corresponding path plan was conducted (shown in Figure $2(\mathrm{c})$ ) at $2.5 \mathrm{~mm} / \mathrm{s}$ and $270^{\circ}$. According to ASTM D3552-96(07), the printed composites were cut to $75 \mathrm{~mm} \times 1 \mathrm{~mm} \times 10 \mathrm{~mm}$ (length $\times$ width $\times$ height). To reduce the influence of the surface roughness on the mechanical properties of composites, the surfaces of these specimens were polished. Five specimens were fabricated for each group. The clamping parts of the specimen were treated with epoxy resin glue.

\section{Results and Discussions}

Since the fiber suppressed the flow of the liquid metal, the cross-sectional shape was not circular and it was difficult to calculate the wire feeding by theoretical calculation (In this paper, wire feeding is expressed as the distance of the wire per $100 \mathrm{~mm}$ of printed monofilament). Hence, research on the forming of the first layer is useful to improve the quality of printing. The mechanical properties and interfacial microstructure of the composites are discussed. Finally, to demonstrate the advantages and innovations of this method, 3D composite structures are shown. 


\subsection{Character of Monofilament}

\subsubsection{Morphology of Monofilament}

The right heating block temperature $\left(T /{ }^{\circ} \mathrm{C}\right)$ should be chosen before printing starts. There is a temperature difference between the nozzle and the heating block $\left(\Delta T /{ }^{\circ} \mathrm{C}\right)$ because of heat dissipation. To ensure that the fiber could be pulled out from the nozzle smoothly, the temperature at the nozzle is required to be higher than the melting temperature of the $\mathrm{Sn}_{50} \mathrm{~Pb}_{50}$ alloy $\left(T_{\mathrm{m}} /{ }^{\circ} \mathrm{C}\right)$, otherwise the nozzle could be blocked. The result can be represented by the following equation:

$$
T \geq T_{\mathrm{m}}+\Delta T_{\min },
$$

where $\Delta T_{\min }$ is the minimum value of $\Delta T$.

According to the law of conservation of energy, the heat released in the monofilament composite within the nozzle (Q) should satisfy the following equation,

$$
Q=Q_{2}+Q_{3}+Q_{1}-Q_{0},
$$

where $Q_{2}$ is the heat transferred along the diameter of the nozzle, $Q_{3}$ is the heat dissipation around the outlet of the nozzle, $Q_{1}$ and $Q_{0}$ are the exported heat and imported heat by the monofilament, respectively. Among them, $Q_{1}$ is approximately equal to $Q_{0}, Q_{3}$ is related to the environmental temperature, and $Q_{2}$ is the main factor. Therefore:

$$
Q \approx Q_{2} \text {. }
$$

According to the definition of thermal conductivity, $Q_{2}$ should satisfy the following equation:

$$
Q_{2}=\int_{0}^{\frac{L}{v}} S_{\text {mono }} \cdot\left(-\frac{\partial T_{2}}{\partial R}\right) \cdot \lambda_{n} \cdot \mathrm{d} t
$$

where $L$ is the distance in the nozzle with a temperature difference, $v$ is the printing velocity, $S_{\text {mono }}$ is the contact area of unit length of the monofilament and the nozzle, $\frac{\partial T_{2}}{\partial R}$ is the temperature gradient in the diameter direction of the nozzle, and $\lambda_{n}$ is the thermal conductivity of nozzle. Because:

$$
Q=c_{\mathrm{m}} \cdot \Delta T_{\min } \cdot m,
$$

Table 2 The printing parameters of monofilament specimens

\begin{tabular}{lllllll}
\hline Wire feeding (mm/mm) & \multicolumn{2}{l}{ Printing velocity $(\mathbf{m m} / \mathbf{s})$} & & Height $(\mathbf{m m})$ & $\begin{array}{l}\text { Temperature } \\
\left({ }^{\circ} \mathbf{C}\right)\end{array}$ \\
\hline $10 / 100$ & 1 & 2 & 3 & 4 & 0.3 & 270 \\
$20 / 100$ & 1 & 2 & 3 & 4 & 0.3 & 270 \\
$30 / 100$ & 1 & 2 & 3 & 4 & 0.3 & 270 \\
$40 / 100$ & 1 & 2 & 3 & 4 & 0.3 & 270 \\
\hline
\end{tabular}

where $c_{\mathrm{m}}$ is the specific heat capacity of the monofilament and $m$ is the mass of unit length of the monofilament.

Bringing Eq. (3) and Eq. (4) into Eq. (5):

$$
\Delta T_{\min }=\frac{\int_{0}^{\frac{L}{v}} S_{\text {mono }} \cdot\left(-\frac{\partial T_{2}}{\partial R}\right) \cdot \lambda_{n} \cdot \mathrm{d} t}{c_{\mathrm{m}} \cdot m} .
$$

It is difficult to calculate $\Delta T_{\min }$ accurately, but the influencing factors can be derived from Eq. (6). It is obvious that $\Delta T_{\min }$ is affected by factors such as printing velocity, nozzle material, nozzle shape, and surface temperature, etc. In addition, it can be used to estimate the $\Delta T_{\min }$ of other materials. According to the experimental results, $\Delta T_{\min }$ should be greater than $60^{\circ} \mathrm{C}$ with our print head. The matrix alloy in the molten cavity is in a liquid state because this temperature greatly exceeds the semi-solid range of the $\mathrm{Sn}_{50} \mathrm{~Pb}_{50}$ alloy. However, in the classical thermoplastic composite printing process, the thermoplastic resin is in a viscous state [25-30] rather than a liquid state that has completely different rheological properties. Finally, the chosen temperature was $270{ }^{\circ} \mathrm{C}$ to improve the superposition performance.

Due to the surface tension of liquid metal, the existing metal extrusion 3D printing technology is usually extruded into a circular or nearly circular shape, which is not conducive to superposition. The FTP method uses fiber to suppress the phenomenon of liquid metal agglomeration, which leads to the circular cross section of the monofilament. Therefore, it is difficult to calculate the wire feeding in the printing process accurately by theoretical calculations; hence, the study of the monofilament morphology becomes necessary. In this paper, the uniformity, width, cross section, and thickness of the composite monofilament specimens with different wire feedings and printing velocities were studied and the groups are shown in Table 2.

It can be seen from Figure 3 that both the wire feeding and printing velocity have a greater influence on the uniformity of the monofilament. Using the same printing velocity, the contour of the fiber bundle appears on the surface of the monofilament and some of the fibers are exposed when the wire feeding is low. As the wire 

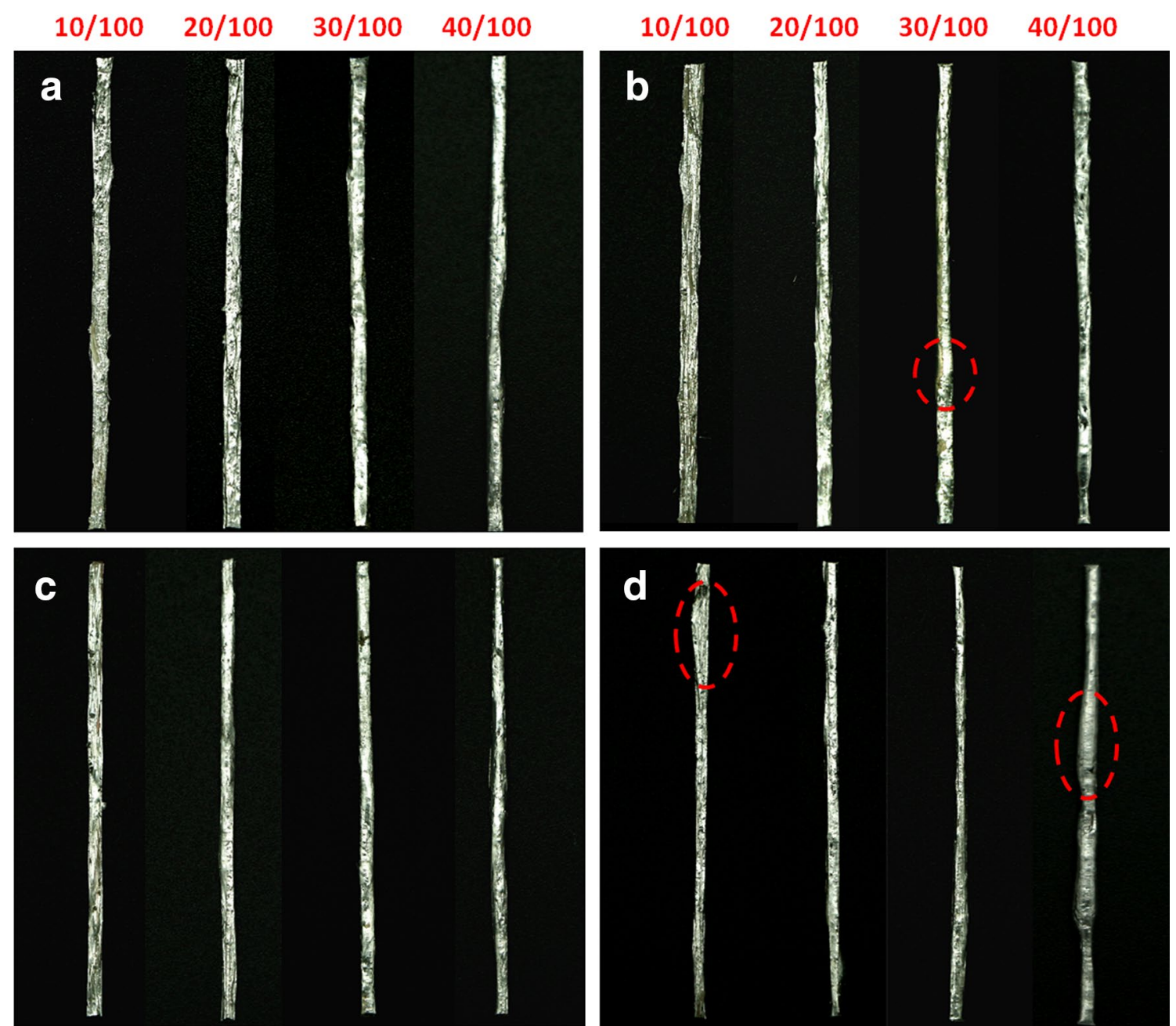

Figure 3 Monofilament morphology of specimens at the printing velocity of (a) $1 \mathrm{~mm} / \mathrm{s},(\mathbf{b}) 2 \mathrm{~mm} / \mathrm{s}$, (c) $3 \mathrm{~mm} / \mathrm{s}$, and (d) $4 \mathrm{~mm} / \mathrm{s}$ and wire feeding of $10 / 100,20 / 100,30 / 100,40 / 100$

feeding is increased, the surface of the monofilament gradually changes, becoming smoother. However, when the wire feeding is too large, it can exceed the control limit of inhibition on the liquid metal flowing. Hence, the liquid metal could flow along the fiber inhomogeneously, as shown in Figure 3(d), and reduce the uniformity of printing. When the wire feeding is equal, the uniformity of printing increases initially and then decreases with increasing printing velocity. It is obvious that the uniformity of the printed monofilament is superior at a printing velocity of $3 \mathrm{~mm} / \mathrm{s}$ and wire feeding of 20/100.

The evolution of the cross-sectional profile of the monofilaments at the different wire feedings is shown in Figure 4(a). When the wire feeding is low, the fiber bundle effectively controls the morphology of the liquid metal, and the cross-sectional profile is roughly rectangular. However, when the wire feeding is large, such as
$30 / 100$ and 40/100, the fiber bundle loses control of the morphology of the liquid metal, and it can be seen that the liquid metal is agglomerated into a circular shape. In addition, when the printing velocity increases, the fibers on both sides shrink inward. When the wire feeding is low and the printing velocity exceeds $4 \mathrm{~mm} / \mathrm{s}$, the pulling force of the fiber separates the middle part of the monofilament from the bottom plate, and the cross section shrinks into a ring as shown in Figure 4(b). The crosssectional shapes of the monofilaments have an enormous influence on the surface roughness and forming density. The circle shape profile, which forms at the wire feeding of 40/100, is not a suitable profile for the accumulation of monofilaments. The porosities would form between monofilaments, and the surface is rough owing to the poor homogeneity of the monofilament with the increasing wire feeding (discussed later). Additionally, 


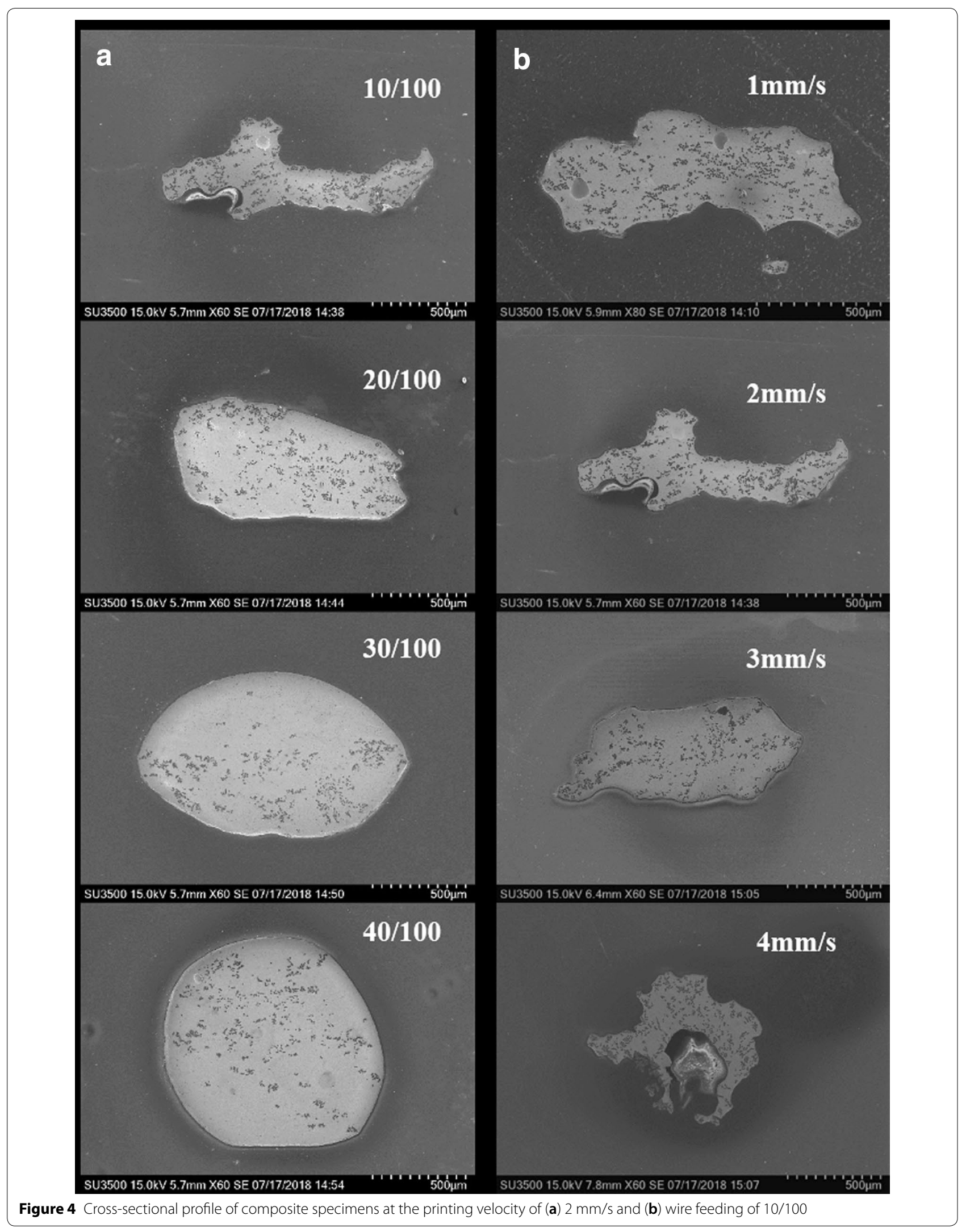


improving the printing velocity also decreases the homogeneity of the monofilament (discussed later), and the cracks and porosities form between the two layers owing to the ring profile.

The average values of width and thickness are also discussed. As shown in Figure 5, it can be seen that when the printing velocity is constant, the width usually does not change with the variation of the wire feeding except for the $4 \mathrm{~mm} / \mathrm{s}$ specimen. However, the width is affected by the printing velocity. With the printing velocity rising, the width is gradually reduced, because the morphology of the monofilament is controlled by the fiber, and its width is mainly affected by the fiber width. At the same time, the printing velocity affects the tension of the fiber, which further changes its distribution density. That is to say, the fiber distribution is denser and the width of the monofilament is smaller when the printing velocity is faster. When the printing velocity is $3 \mathrm{~mm} / \mathrm{s}$, the uniformity of the monofilament is favorable. All of the above is in accordance with previous observations.

The thickness is mainly affected by the wire feeding (Figure 6). With the wire feeding increasing, both the thickness and error increase, which means the uniformity of the monofilament decreases. This is because the matrix stacks in the direction of thickness when the width remains constant.

\subsubsection{Printing Precision of Monofilament with Different Angles}

Unlike the printing of pure metals, the deformation occurs in this process when printing corners, because of the dragging of one fiber. The errors are not only affected by the printing process, but also by the angle of the corner.

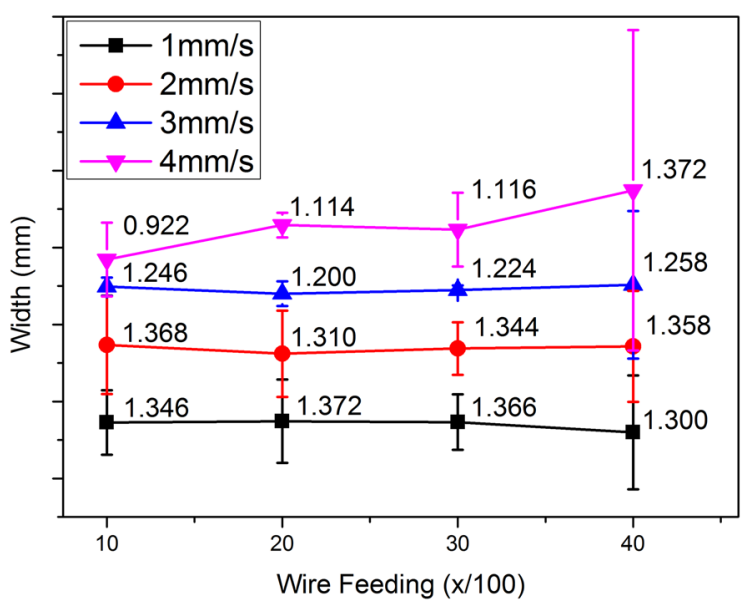

Figure 5 Width-wire feeding of specimens at different printing velocities

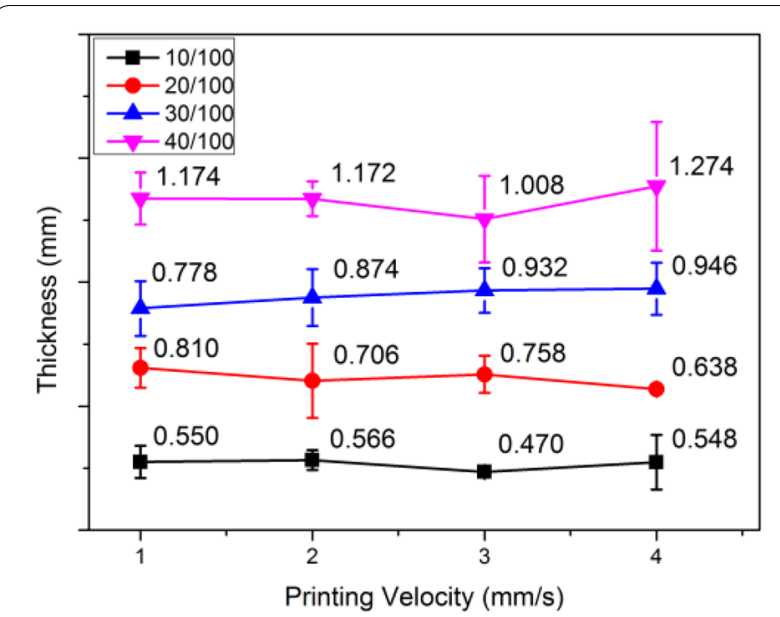

Figure 6 Thickness-printing velocity of specimens at different amounts of wire feeding

The printing of a monofilament with the same angle under different processes is shown in Figure 7 and the errors in the $x$ and $y$ directions are shown in Table 3 . On the one hand, the slow printing velocity reduces the errors in the $x$ and $y$ directions. Additionally, the errors can be further reduced if the nozzle stays at the apex of the corner for several seconds. On the other hand, when the value of the rotation angle $\theta$ gradually increases, the errors in the $x$ and $y$ directions gradually decrease in the group of $1 \mathrm{~mm} / \mathrm{s}$ velocity and $3 \mathrm{~s}$ pause $(1 \mathrm{~mm} / \mathrm{s}+3 \mathrm{~s})$. At $150^{\circ}$, the error in the $x$ and $y$ directions is negligible, regardless.

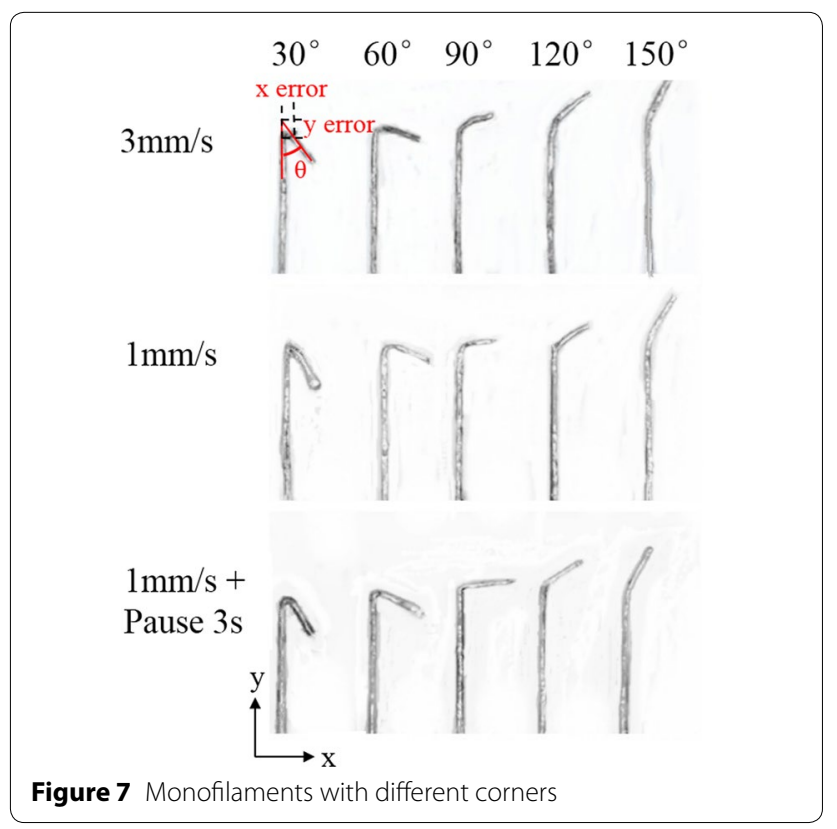


Table 3 The error of the corners in $x$ and $y$ direction

\begin{tabular}{|c|c|c|c|c|c|}
\hline Group & $\begin{array}{l}30^{\circ} \\
x \text { error }(\mathrm{mm})\end{array}$ & $\begin{array}{l}60^{\circ} \\
x \text { error }(\mathrm{mm})\end{array}$ & $\begin{array}{l}90^{\circ} \\
x \text { error }(\mathrm{mm})\end{array}$ & $\begin{array}{l}120^{\circ} \\
x \text { error }(\mathrm{mm})\end{array}$ & $\begin{array}{l}150^{\circ} \\
x \text { error }(\mathrm{mm})\end{array}$ \\
\hline $3 \mathrm{~mm} / \mathrm{s}$ & 2.95 & 5.1 & 5.54 & 1.75 & 0 \\
\hline $1 \mathrm{~mm} / \mathrm{s}$ & 1.94 & 3.16 & 2.44 & 1.39 & 0 \\
\hline \multirow[t]{2}{*}{$1 \mathrm{~mm} / \mathrm{s}+3 \mathrm{~s}$} & 1.88 & 1.25 & 0.86 & 0 & 0 \\
\hline & $y$ error $(\mathrm{mm})$ & $y$ error $(\mathrm{mm})$ & $y$ error $(\mathrm{mm})$ & $y$ error $(\mathrm{mm})$ & $y$ error $(\mathrm{mm})$ \\
\hline $3 \mathrm{~mm} / \mathrm{s}$ & 4.68 & 4.36 & 3.32 & 2.11 & 0 \\
\hline $1 \mathrm{~mm} / \mathrm{s}$ & 3.73 & 2.89 & 2.36 & 1.31 & 0 \\
\hline $1 \mathrm{~mm} / \mathrm{s}+3 \mathrm{~s}$ & 2.67 & 1.57 & 0.9 & 0 & 0 \\
\hline
\end{tabular}

The error in the $x$ direction is the distance in the $x$ direction where the monofilament moves relatively. This distance is mainly affected by the velocity component in the $x$ direction and the error in the $y$ direction. The error in the y direction is affected by the velocity component in the $y$ direction and the dragging force of the monofilament in the $-y$ direction. Therefore, the velocity components in the $x$ and $y$ directions are reduced when the printing velocity is slowed down, and so is the error. As the angle $\theta$ is gradually increased, the interaction force of the monofilament in the $-y$ direction becomes smaller, and the error in the $y$ direction decreases. At the same time, the error in the $x$ direction shows different laws of change under various conditions since the velocity component in the $x$ direction increases. An empirical equation could be used to represent the error variation in the $y$ direction:

$$
y_{e} \approx y_{e}^{0}+a,
$$

where $y_{e}$ is the actual error in the $y$ direction, $y_{e}^{0}$ is the error in the $y$ direction without pause, a is a constant. When the printing velocity is $1 \mathrm{~mm} / \mathrm{s}$ and the pause time is $3 \mathrm{~s}$, the value of $a$ is 1.36 .

\subsection{Interfacial Microstructure}

The typical interfacial microstructures of the $1.0 \mathrm{Cu}-\mathrm{Cf} /$ $\mathrm{SnPb}$ and $3.0 \mathrm{Cu}-\mathrm{Cf} / \mathrm{SnPb}$ specimens are shown in Figure 8. It is obvious that several defects appeared in the $1.0 \mathrm{Cu}-\mathrm{Cf} / \mathrm{SnPb}$ specimen, while no obvious defects were observed in the $3.0 \mathrm{Cu}-\mathrm{Cf} / \mathrm{SnPb}$ specimen. In addition, the fibers were uniformly distributed in each layer and there was a distinct matrix layer between different fibrous layers as a transition. Magnifying the image ten times, it can be seen that the interfacial layer of the $1 \mu \mathrm{m}$ specimen was thin and the wettability between the liquid metal and the fiber was good, while the interfacial layer of the $3.0 \mathrm{Cu}-\mathrm{Cf} / \mathrm{SnPb}$ specimen was thicker and there were closed pores between the multiple fibers, which formed during the coating process.
Obviously, the fiber and the matrix were combined by the wetting behavior and the capillarity in the FTP process. The composite monofilament left the nozzle under traction and was then deposited on the bottom. In this process, no additional pressure is generated in the melting chamber. However, the classical thermoplastic composite printing process is just the opposite. The feeding of wire creates a pressure in the filled melt cavity, which becomes the power of combination and subsequent deposition. As such, the combination and deposition mechanisms of the FTP process and the classical thermoplastic composite printing process are completely different.

Generally, the thickness of the fibrous coating was limited. The preparation of a $3 \mu \mathrm{m}$ thick interfacial layer usually requires repeated plating processes, which tends to cause bonding between the fibers to form a closed hole as shown in Figure 8(b). All of the above would have an impact on the mechanical properties of the composite. Therefore, it is essential to select the carbon fiber with a suitable thickness of interfacial layer according to actual requirements.

\subsection{Mechanical Properties}

Since the mechanical properties of low melting alloys are generally poor, it is difficult to use them directly as structural materials, which limits their further applications. In the process the continuous fiber not only plays a role in controlling the morphology of the liquid metal, but also greatly improves the mechanical properties of the alloy. The tensile properties of the composites are studied in this paper.

The fractured tensile specimen is shown in Figure 9(a) and the experimental results are shown in the Table 4 . The tensile strength of the $\mathrm{Sn}_{50} \mathrm{~Pb}_{50}$ alloy was $33.3 \mathrm{MPa}$. When the thickness of the $\mathrm{Cu}$ fiber coating was $3 \mu \mathrm{m}$, the tensile strength was higher $(235.2 \mathrm{MPa})$. Reducing the thickness of the $\mathrm{Cu}$ coating from $3 \mu \mathrm{m}$ to $1 \mu \mathrm{m}$ under the same condition of layer height and wire feeding, the volume of fiber (VOF) was reduced from $21.25 \%$ 

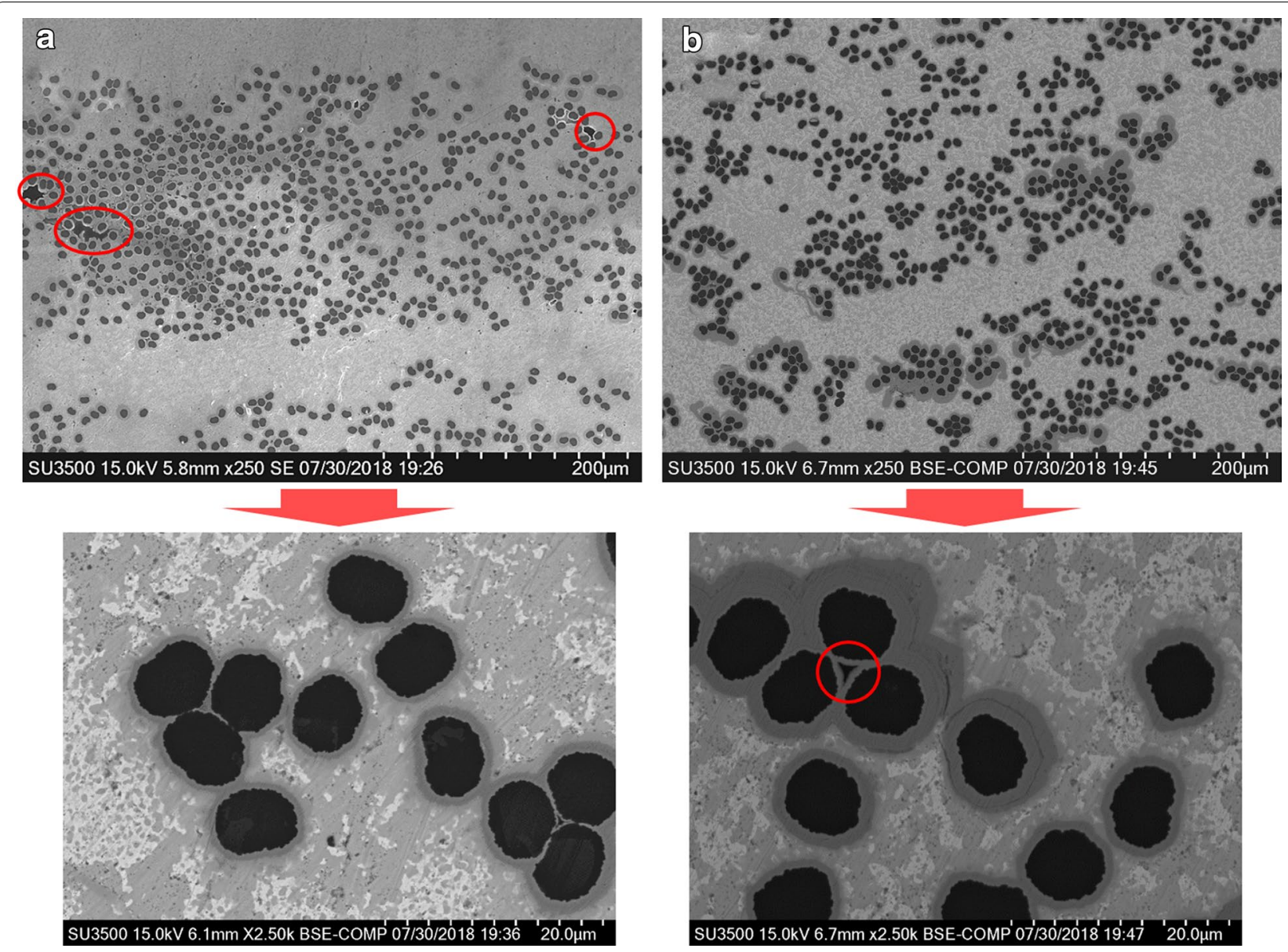

Figure 8 The interfacial microstructure of (a) $1 \mu \mathrm{m}$ Cu coating specimen and (b) $3 \mu \mathrm{m}$ Cu coating specimen

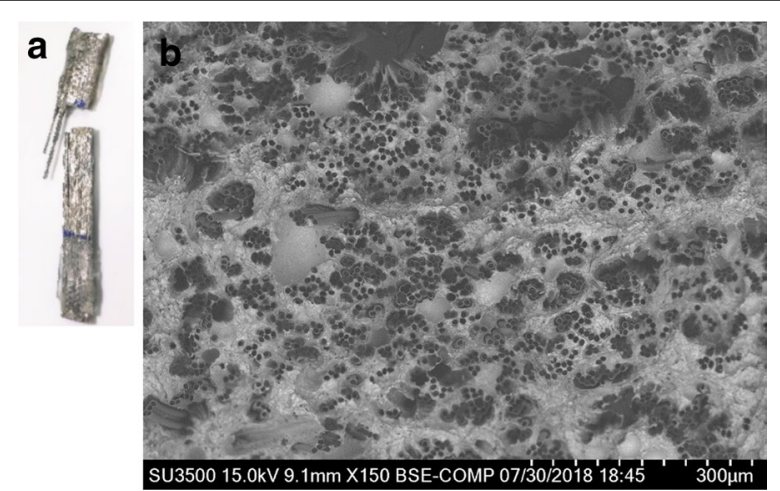

Figure 9 (a) Tensile specimen of FTP process and (b) the fracture morphology BSE image of $1 \mu \mathrm{m}$ specimen

to $12.14 \%$. The reference date shows that the maximum tensile strength of the copper-plated carbon fiber reinforced $\mathrm{SnPb}$ alloy prepared by a squeeze casting process was $240 \mathrm{MPa}$ (the VOF was $15 \%$ ). The preparation
Table 4 The tensile strength of $\mathrm{C}_{\mathrm{f}} / \mathrm{Sn}_{50} \mathrm{~Pb}_{50}$ composite and $\mathrm{Sn}_{50} \mathrm{~Pb}_{50}$ alloy

\begin{tabular}{lll}
\hline & Tensile strength (MPa) & VOF (\%) \\
\hline 3.0Cu-Cf/SnPb & $235.2 \pm 23.6$ & 21.25 \\
1.0Cu-Cf/SnPb & $227.7 \pm 5.6$ & 12.14 \\
Reference date [19] & $240.0 \pm 15$ & 15 \\
$\mathrm{Sn}_{50} \mathrm{~Pb}_{50}$ alloy & $33.3 \pm 0.5$ & - \\
Rule of mixture & 393.5 & 12.14 \\
\hline
\end{tabular}

performance of the FTP process was close to the traditional preparation process. According to the rule of mixture, the theoretical maximum is $393.5 \mathrm{MPa}$ when the VOF is $12.14 \%$. The tensile strength of the printed composite was less than the value of rule of mixture, and similar to that of copper. The process could be further improved to increase this performance.

Figure 10 shows the typical tensile strength-strain curve of $1.0 \mathrm{Cu}-\mathrm{Cf} / \mathrm{SnPb}$ and $3.0 \mathrm{Cu}-\mathrm{Cf} / \mathrm{SnPb}$. Both 


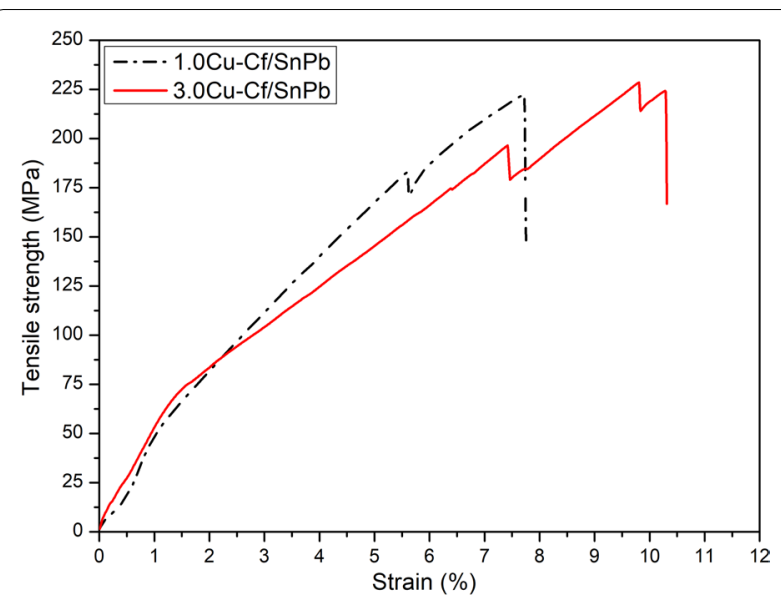

Figure 10 Typical tensile strength-strain curve of the printed composite specimens

of the composites are brittle fracture, and the turn line indicates that the interlayer bonding, which has an influence on the mechanical properties, could be improved. The backscattered electron (BSE) image of the fracture morphology is shown in Figure 9(b). It can be seen that the fracture morphology of the composite material was relatively flat, and few fibers were pulled out. The surface of the fiber was still coated with a $\mathrm{Cu}$ layer and the fracture morphology of the matrix exhibited a distinct dimple-like texture.

\subsection{Direct Printing of 3D Composite Structures}

To demonstrate the advantages of this process in forming, a hexagonal grid of 5 layers $(0.5 \mathrm{~mm}$ per layer $)$ and a triangle grid of 10 layers $(0.3 \mathrm{~mm}$ per layer $)$ were printed by the FTP process, as shown in Figure 11.

\section{Conclusions}

(1) A novel 3D printing method of continuous fiber reinforced metal matrix composite is proposed in this paper, which uses the fiber bundle to wet with the liquid metal and to control the morphology of the liquid metal, differentiating it from the classic 3D printing process of thermoplastic composite.

(2) The uniformity of the monofilament was affected by the printing velocity and the wire feeding rate. The fiber effectively controlled the morphology of the liquid metal at low wire feeding rate, and the shape of cross-section profile was rectangular. The width of the monofilament decreased with increasing printing velocity. The thickness of the monofilament increased with improving wire feeding rates, and the value of 20/100 was optimal.

(3) When printing a corner, the slower velocity reduced errors in both the $x$ and $y$ directions. By process optimization, the errors in the $x$ and $y$ directions were eliminated when the printing angle was greater than $120^{\circ}$.

(4) There were several defects in $1.0 \mathrm{Cu}-\mathrm{Cf} / \mathrm{SnPb}$, while no obvious defects were observed in $3.0 \mathrm{Cu}-\mathrm{Cf} /$ $\mathrm{SnPb}$. The 3.0Cu-Cf/SnPb exhibited a higher tensile strength of $235.2 \mathrm{MPa}$ and the volume of fiber was $21.25 \%$. It far exceeded the tensile strength of the $\mathrm{SnPb}$ alloy of $33.3 \mathrm{MPa}$ and was close to the tensile strength of the $\mathrm{SnPb}$ composite prepared using the squeeze casting process in reference. This means that the preparation performance of the FTP process was close to the traditional preparation process.

This method could be extended to the preparation of other continuous fiber reinforced metal matrix composites, such as $\mathrm{Cf} / \mathrm{Al}, \mathrm{Cf} / \mathrm{Mg}$, etc.
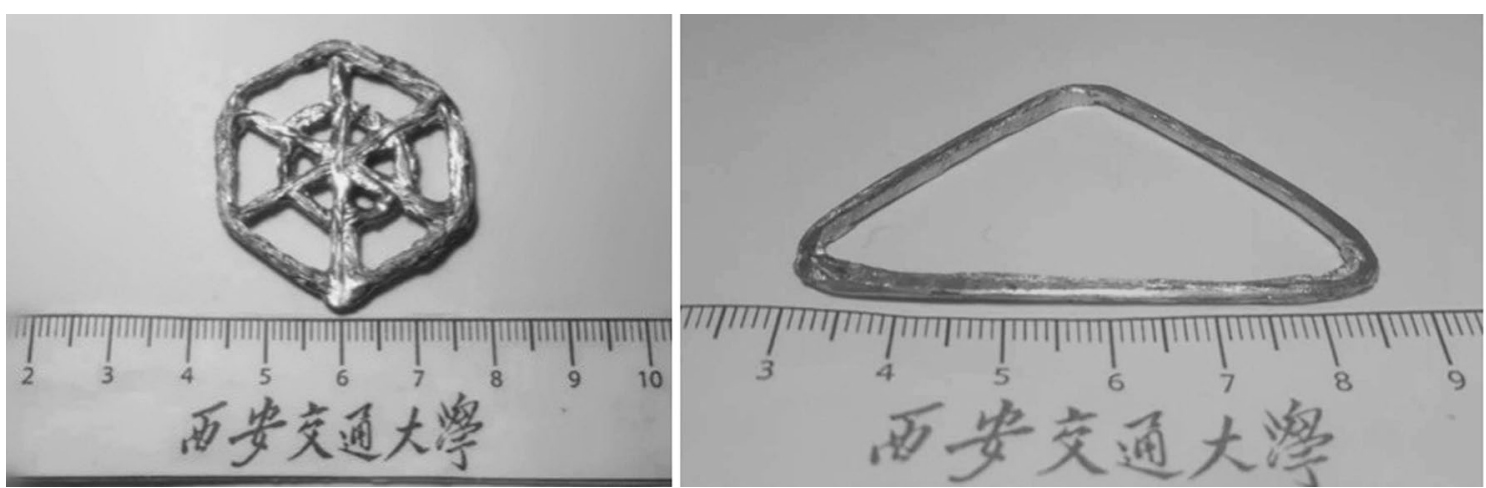

Figure 11 A hexagonal grid and a triangle grid printed by FTP process 


\section{Acknowledgements}

We thank Mr. Zijun Ren at Instrument Analysis Center of Xi'an Jiaotong University for their assistance with SEM analysis, and gratefully acknowledges the support of K. C. Wong Education Foundation.

\section{Authors' Contributions}

$\mathrm{DL}$ was in charge of the whole trial; XW wrote the manuscript; XT and QL assisted with sampling and laboratory analyses. All authors read and approved the final manuscript.

\section{Authors' Information}

Xin Wang, born in 1989, is currently a PhD candidate at State Key Laboratory of Manufacturing Systems Engineering, Shaanxi Engineering Research Center for Rapid Manufacturing Technology, Xi'an Jiaotong University, China. He received his bachelor degree from Northwestern Polytechnical University, China, in 2011. His research interests include metal matrix composites and additive manufacturing techniques.

Xiaoyong Tian, born in 1981, is currently a professor at State Key Laboratory of Manufacturing Systems Engineering, Shaanxi Engineering Research Center for Rapid Manufacturing Technology, Xi'an Jiaotong University, China. His research interests include automatic additive manufacturing and composites molding techniques.

Qin Lian, is currently an associate professor at State Key Laboratory of Manufacturing Systems Engineering, Shaanxi Engineering Research Center for Rapid Manufacturing Technology, Xi'an Jiaotong University, China. Her research interests include additive manufacturing process and equipment, and biomanufacturing.

Dichen Li, born in 1964, is currently Changjiang distinguished professor, the director of State Key Laboratory of Manufacturing Systems Engineering, Shaanxi Engineering Research Center for Rapid Manufacturing Technology, Xi'an Jiaotong University, China. His research interests include manufacturing process and equipment, rapid prototyping manufacturing technology and biomanufacturing.

\section{Funding}

Supported by National Key R\&D Program of China (Grant Nos.

2017YFB1 103400, 2016YFB1 100902), National Natural Science Foundation of China (Grant No. 51575430, 51811530107) and The Youth Innovation Team of Shaanxi Universities.

\section{Availability of Data and Materials}

The datasets supporting the conclusions of this article are included within the article.

\section{Competing Interests}

The authors declare no competing financial interests.

\section{Author Details}

1 State Key Laboratory of Manufacturing Systems Engineering, Xi'an Jiaotong University, Xi'an 710049, China. ${ }^{2}$ Shaanxi Engineering Research Center for Rapid Manufacturing Technology, Xi'an 710049, China.

Received: 1 September 2018 Revised: 13 March 2020 Accepted: 28 March 2020

Published online: 10 April 2020

\section{References}

[1] K Lu. The future of metals. Science, 2010, 328(5976): 319-320.

[2] H A Hegab. Design for additive manufacturing of composite materials and potential alloys: A review. Manufacturing Review, 2016, 3: 1-17

[3] A Dey, K M Pandey. Characterization of fly ash and its reinforcement effect on metal matrix composites: A review. Reviews on Advanced Materials Science, 2016, 44(2): 168-181.

[4] K Shirvanimoghaddam, S U Hamim, M KarbalaeiAkbari, et al. Carbon fiber reinforced metal matrix composites: Fabrication processes and properties. Composites Part A: Applied Science and Manufacturing, 2017, 92: 70-96.
[5] TB Sercombe, $X$ Li. Selective laser melting of aluminium and aluminium metal matrix composites: review. Materials Technology, 2016, 31(2): 77-85.

[6] BV Ramnath, C Elanchezhian, R M Annamalai, et al. Aluminium metal matrix composites - A review. Reviews on Advanced Materials Science, 2014, 38(1): $55-60$.

[7] S Attar, M Nagaral, H N Reddappa, et al. A review on particulate reinforced aluminum metal matrix composites. Journal of Emerging Technologies and Innovative Research, 2015, 2(2): 225-229.

[8] J Singh. Fabrication characteristics and tribological behavior of $\mathrm{Al} / \mathrm{SiC} / \mathrm{Gr}$ hybrid aluminum matrix composites: A review. Friction, 2016, 4(3): 191-207.

[9] S S Sidhu, A Batish, S Kumar. Fabrication and electrical discharge machining of metal-matrix composites: A review. Journal of Reinforced Plastics and Composites, 2013, 32(17): 1310-1320.

[10] S Liu, Y Li, N Li. A novel free-hanging 3D printing method for continuous carbon fiber reinforced thermoplastic lattice truss core structures. Materials \& Design, 2018, 137: 235-244.

[11] Y Ming, Y Duan, B Wang, et al. A novel route to fabricate high-performance 3D printed continuous fiber-reinforced thermosetting polymer composites. Materials, 2019, 12(9): 1369.

[12] Dichen L, Jiankang $H$, Xiaoyong T, et al. Additive manufacturing: integrated fabrication of macro/microstructures. Journal of Mechanical Engineering, 2013, 49(06): 129-135. (in Chinese)

[13] D Herzog, V Seyda, EWycisk, et al. Additive manufacturing of metals. ActaMaterialia, 2016, 117: 371-392.

[14] H Warren-Forward, P Cardew, B Smith, et al. A comparison of dose savings of lead and lightweight aprons for shielding of $99 \mathrm{~m}$-Technetium radiation Radiation Protection Dosimetry, 2007, 124(2): 89-96.

[15] J X Wen, W N Wang, Q Guo, et al. Gamma-ray radiation on magneto-optical property of Pb-doped silica fiber. Journal of Inorganic Materials, 2018, 33(4): 416-420.

[16] M Kurudirek. Effective atomic number, energy loss and radiation damage studies in some materials commonly used in nuclear applications for heavy charged particles such as $\mathrm{H}, \mathrm{C}, \mathrm{Mg}, \mathrm{Fe}, \mathrm{Te}, \mathrm{Pb}$ and $\mathrm{U}$. Radiation Physics and Chemistry, 2016, 122: 15-23.

[17] J Mireles, H C Kim, I H Lee, et al. Development of a fused deposition modeling system for low melting temperature metal alloys. Journal of Electronic Packaging, 2013, 135(1).

[18] CT Ho. Wear of carbon fibre-reinforced tin-lead alloy composites. Journal of Materials Science Letters, 1997, 16: 1767-1770.

[19] CTHo. Nickel- and copper-coated carbon fibre reinforced tin-lead alloy composites. Journal of Materials Science, 1996, 31(21): 5781-5786.

[20] CT Ho. Carbon-fiber-reinforced tin-lead alloy composites. Journal of Materials Research, 1994, 9(8): 2144-2147.

[21] CTHo, D D L Chung. Carbon-fiber reinforced tin-lead alloy as a low thermal-expansion solder preform. Journal of Materials Research, 1990, 5(6): $1266-1270$.

[22] K C Mills, Y C Su. Review of surface tension data for metallic elements and alloys: Part 1 - Pure metals. International Materials Reviews, 2006, 51(6): 329-351.

[23] J Bico, B Roman, L Moulin, et al. Elastocapillary coalescence in wet hair. Nature, 2004, 432(7018): 690

[24] R Cunningham, S P Narra, T Ozturk, et al. Evaluating the effect of processing parameters on porosity in electron beam melted Ti-6Al-4V via synchrotron X-ray microtomography. JOM, 2016, 68(3): 765-771.

[25] C C Yang, XY Tian, T F Liu, et al. 3D printing for continuous fiber reinforced thermoplastic composites: mechanism and performance. Rapid Prototyping Journal, 2017, 23(1): 209-215.

[26] XYTian, TF Liu, C C Yang, et al. Interface and performance of 3D printed continuous carbon fiber reinforced PLA composites. Composites Part a-Applied Science and Manufacturing, 2016, 88: 198-205.

[27] XYTian, TF Liu, Q R Wang, et al. Recycling and remanufacturing of 3D printed continuous carbon fiber reinforced PLA composites. Journal of Cleaner Production, 2017, 142: 1609-1618.

[28] Z Hou, XTian, Z J hang, et al. 3D printed continuous fibre reinforced composite corrugated structure. Composite Structures, 2018, 184: 1005-1010.

[29] M Luo, XTian, W Zhu, et al. Controllable interlayer shear strength and crystallinity of PEEK components by laser-assisted material extrusion. Journal of Materials Research, 2018, 33(11): 1632-1641.

[30] X Wang, M Jiang, Z W Zhou, et al. 3D printing of polymer matrix composites: A review and prospective. Composites Part B-Engineering, 2017, 110 $442-458$. 